\title{
O PREPARO DA ORGANIZAÇÃO PARA EXPANSÃO
}

WINSTON OBERG

De que forma pode a emprêsa ser adaptada ao padrão ideal de organização ?

Quando uma emprêsa é formada por um indivíduo ou grupo de indivíduos, o trabalho é dividido de maneira bastante informal entre a equipe original de empregados. E possivel que diversos funcionários estejam encarregados das mesmas coisas e, à medida que seus interêsses mudem, sejam transferidos de um para outro departamento da emprêsa, como, por exemplo, de produção para vendas, de vendas para tinanças etc.

Entretanto, gradualmente, cada funcionário acaba por especializar-se no tipo de trabalho pelo qual tenha mais interêsse ou que possa melhor realizar. Assim, ainda que a emprêsa não reconheça formalmente a estrutura desenvolvida pela fixação de especializações, essa estrutura existe e pode, a qualquer momento, ser representada num organograma.

E nosso entender que todo o administrador de cúpula deveria dar-se ao trabalho de desenhar a estrutura de sua organização. Sabemos que é possível que uma emprêsa cresça sem um organograma. De fato, algumas se tornaram prósperas sem aplicá-lo. Entretanto, quase invariàvelmente, depois de ter desenhado seu primeiro organograma, verifica o administrador que a organização não se desenvolveu tão lògicamente quanto deveria.

WINSTON OBERG - Professor de Administração de Emprêsas da «Michigan State University». 


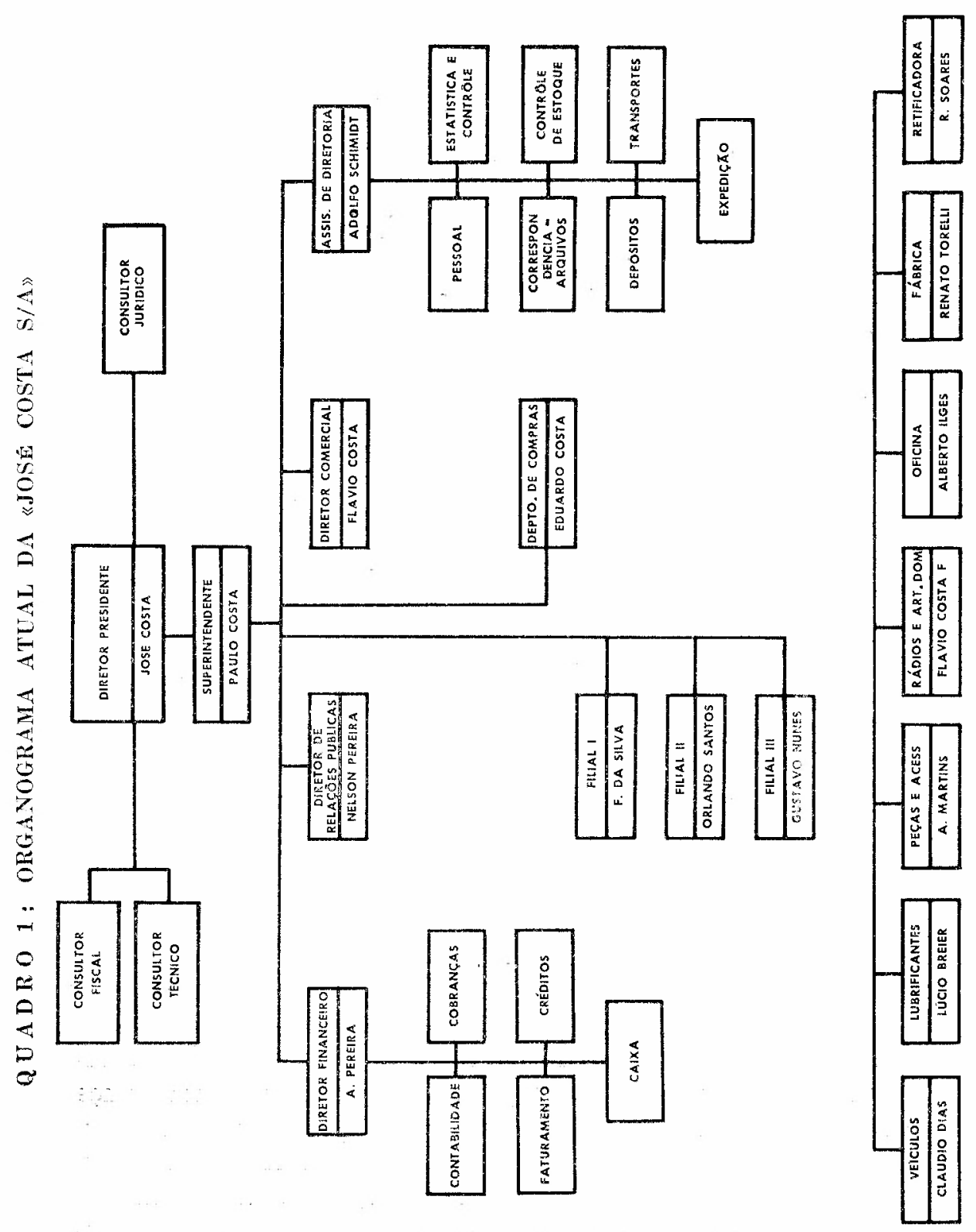




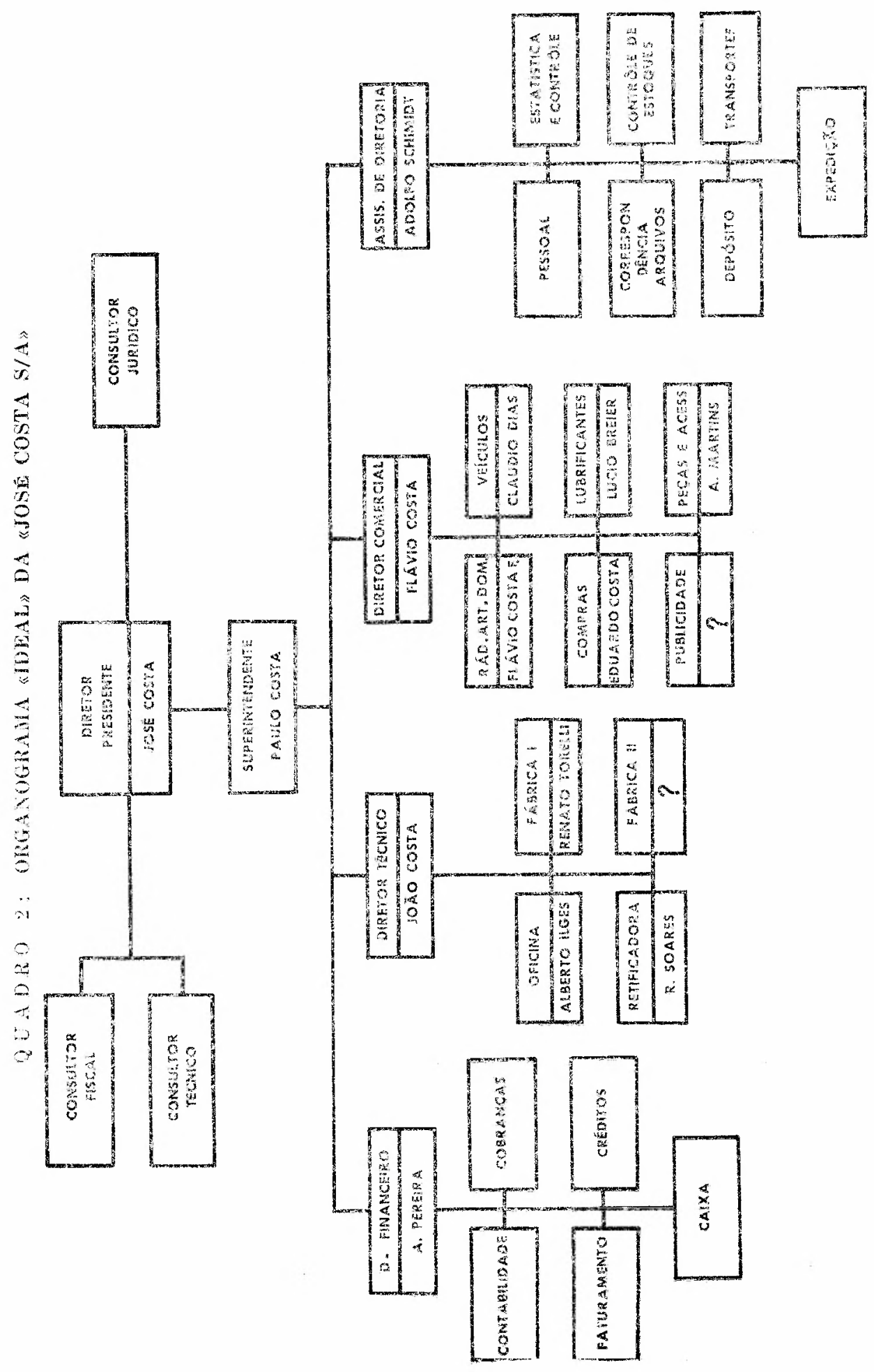


E nosso objetivo, neste artigo, examinar em pormenor uma das aplicações do organograma: a adaptação da organização existente à ideal. Depois de algumas considerações explanatórias, daremos um exemplo em que será ilustrado o uso, para êste fim, que se faz do organograma.

\section{A Expansão e o Organograma "Ideal"}

As organizações não podem ser mudadas da noite para o dia sem a criação de muitos efeitos indesejáveis. Em uma emprêsa em expansão, no entanto, as oportunidades para mudanças surgem muito freqüentemente. Assim, deveria o administrador, além do retrato de sua organização, ter, em sua escrivaninha, um segundo organograma : um quadro do que a organização, a seu ver, deve ser.

Ao desenhar o organograma "ideal" para sua emprêsa, o dirigente poderá usá-lo como modêlo a ser seguido quando surjam oportunidades para mudanças. A medida que seja acrescentado um nôvo departamento, adquirida uma nova fábrica ou fabricado um nôvo produto, será possível, através dêsse organograma, mudar a organização no sentido do ideal.

O modo de preparar o organograma "ideal" é bastante simples : colocam-se, em cada posição administrativa, nome, idade e indicação quanto à possibilidade de avanço, na organização, de cada administrador da emprêsa. A indicação de possibilidade de promoção, por ser variável, pode ser feita, no organograma, em diferentes côres : uma côr pode indicar o administrador que deva ser substituído; outra aquêle que esteja preparado para promoção imediata e específica; outra, ainda, aquêle que, embora realizando um trabalho satisfatório, não esteja preparado para ser promovido; outra, finalmente, o indivíduo que, por ainda não ter experiência, não esteja realizando bem sua função, mas que poderá melhorar com o decorrer do tempo.

Representados, assim, os administradores da emprêsa, é grandemente facilitada a tarefa de tornar mais eficiente a organização, através de um melhor aproveitamento do talento administrativo de que dispõe. 
Preparo da Organização Ideal : Exemplo

A fim de tornar clara a elaboração do organograma ideal, daremos, aqui, um exemplo de sua aplicação. Tomaremos uma emprêsa nacional a que chamaremos de "José Costa S/A", localizada em São Paulo.

A Companhia Costa tem cêrca de 40 anos de existência e foi fundada por José costa, quando êste tinha 30 anos de idade. Hoje, o SR. JosÉ costa ainda goza de boa saúde, mas está desejando livrar-se da responsabilidade de dirigir as operações diuturnas da emprêsa. Assim, êle gostaria de transferir-se para uma posição consultiva, na companhia, dentro dos próximos quatro ou cinco anos e entregar a direção da mesma a seus filhos.

O SR. JOSÉ costa tem três filhos e um genro. Dois dos filhos, FLÁvio, com 44 anos e EDUARDo, com 38, estão trabalhando na companhia. JoÃo, com 42, trabalhou para a companhia durante muitos anos, tendo saído para assumir a alta administração de outra emprêsa, de propriedade de seus tios, localizada no sul do país. JoÃo poderia voltar à "José Costa S/A", pois prefere morar em São Paulo, onde reside a família de sua espôsa.

O genro do SR. JOSÉ COSTA, RENATO TORELLI, com 31 anos de idade, o irmão de JosÉ, PAUlo, com 67 anos e o cunhado de JOSÉ, ARMANDO PEREIRA, com 64 anos, também ocupam posições administrativas na emprêsa. Além dêstes, NELSON, irmão de ARMANDo, com 55 anos, é elemento de direção da companhia e o neto de JosÉ, FLÁvio costa FILHo, com 21 anos, nela ingressou em janeiro, depois de ter obtido o diploma de contador.

JosÉ é um homem progressista e recentemente contratou uma firma de consultores de administração para aconselhá-lo nos problemas da emprêsa. Além do problema relativo a seu afastamento gradual da companhia, José tem outro, mais imediato : sua firma está com um atraso de seis meses no atendimento de pedidos e êle se dá conta de que terá que ex- 


\section{Q U A D $\mathrm{H} O \mathrm{O} \quad 3$}

ORGANOGRAMA ATUAL DA "JOSE COSTA S/A\# COM VAGAQ PARA POSEIVEIS OCTPATTES

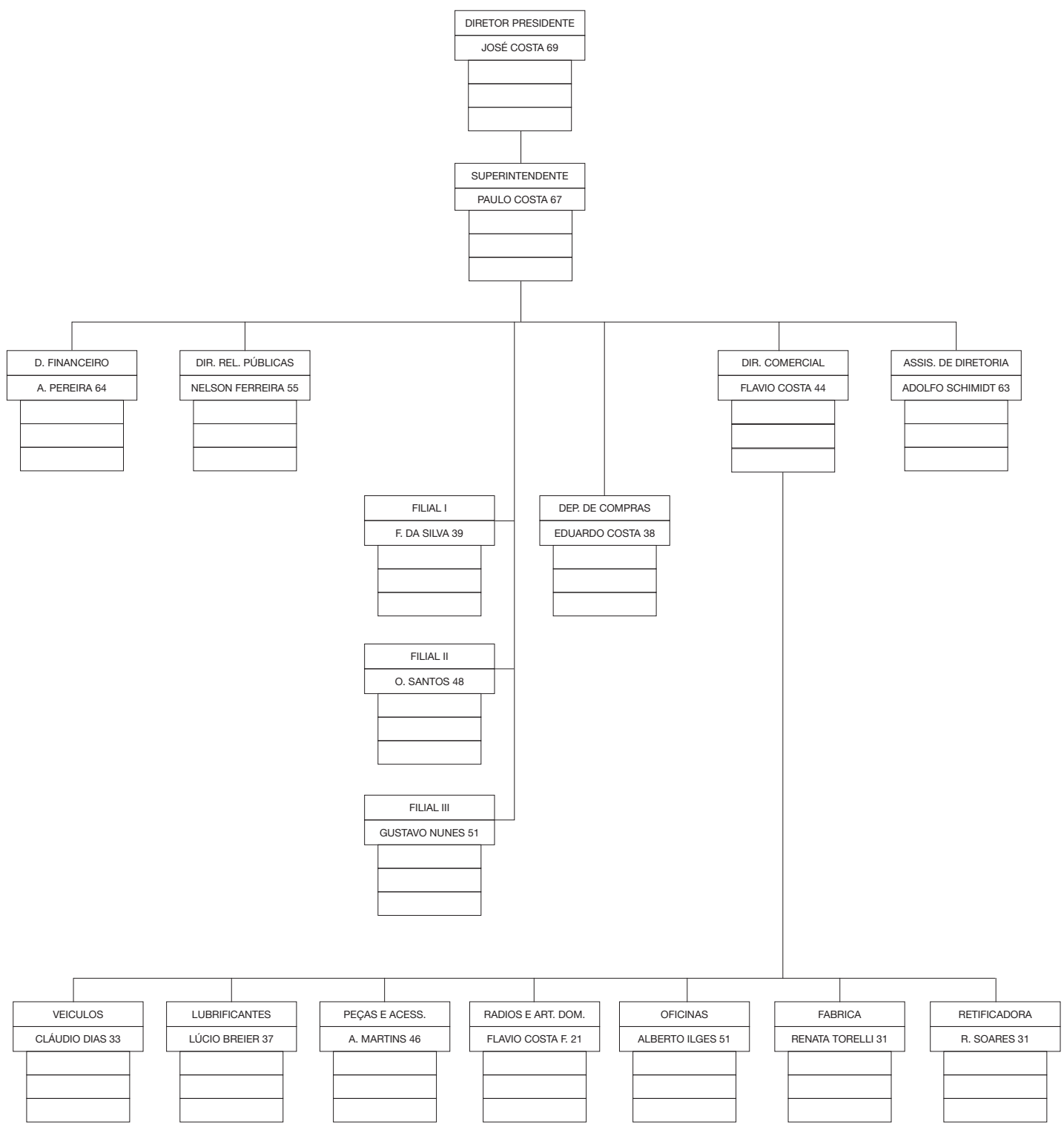


$\mathrm{Q} \quad \mathrm{U} A \mathrm{I} \quad \mathrm{R} O \mathrm{O}$

ORGANOGRAMA ATHAL MA UOSE COSTA S/A》 COY

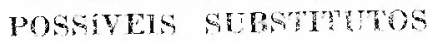

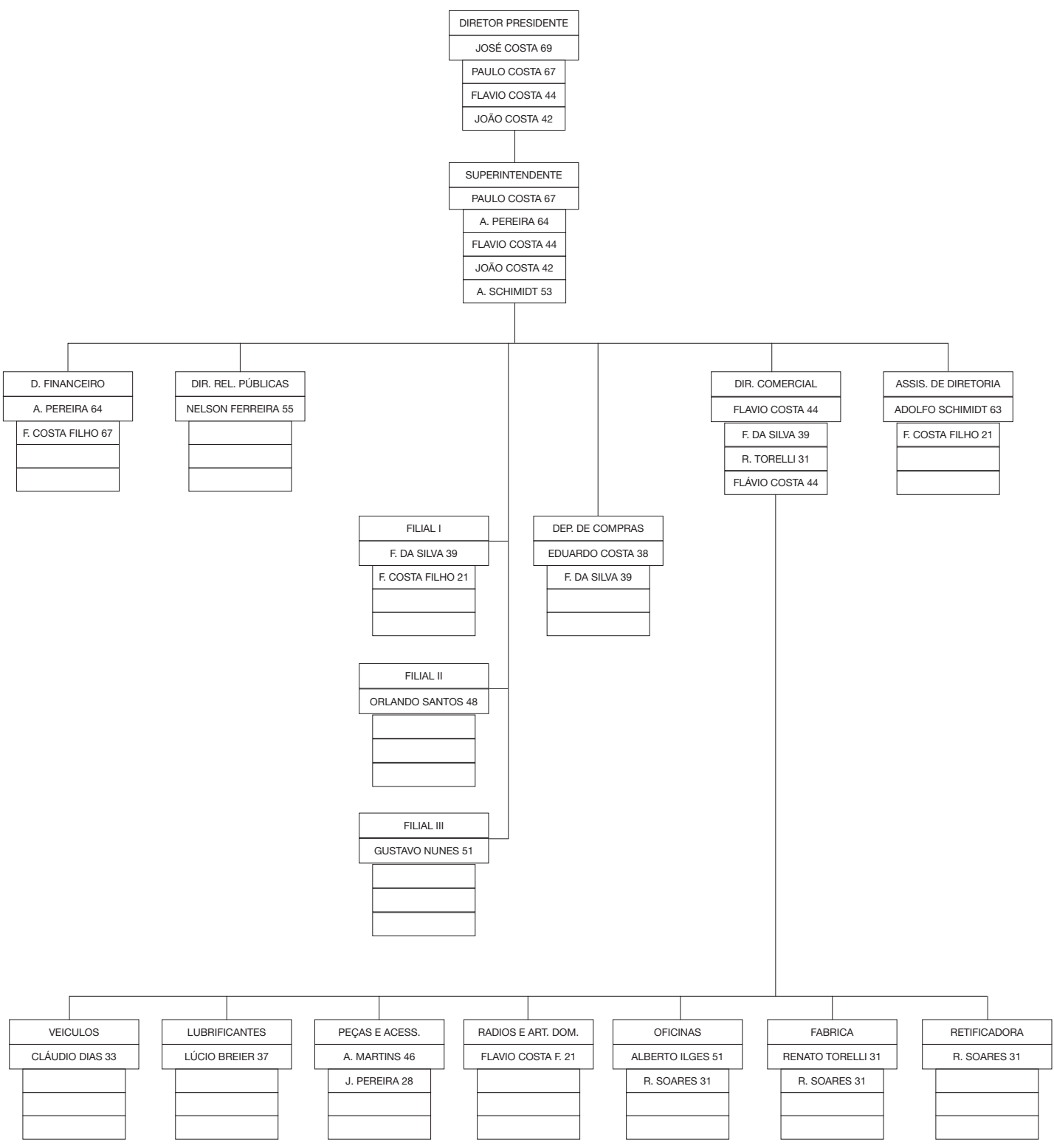


pandir a produção, provàvelmente pela construção de uma nova fábrica.

Os consultores contratados por José pediram-lhe que desenhasse a estrutura da organização da emprêsa. Depois de diversos rascunhos, JosÉ finalmente se deu por satisfeito e apresentou-lhes o organograma constante do Quadro 1.

José, a seguir, desenhou, ainda a pedido dos consultores, um segundo organograma, aquêle que deverá existir depois da aquisição da nova fábrica (Vide Quadro 2).

\section{A Organização Ideal e o Quadro de Substituições}

Depois de JosÉ ter avaliado cada um dos administradores de sua companhia, os consultores desenharam um organograma de substituição, utilizando as seguintes côres : (Vide Quadro 3).

Vermelho - para os administradores que devem ser substituídos, quer porque estejam fazendo trabalho insatisfatório, quer porque estejam abandonando a emprêsa, por aposentadoria, ou motivos de saúde;

azul - para os indivíduos que estão preparados para promoção ;

amarelo - para aquêles que estão trabalhando satisfatòriamente, mas não podem scr promovidos; e

verde - para os administradores que não têm experiência em seu trabalho e que não estão, portanto, realizando-o satisfatòriamente. Estes indivíduos entretanto, ao adquirir experiência, poderão vir a preencher bem suas funções.

O SR. JOSÉ COSTA verificou, então, que o quadro de substituições podia ser também encarado como um quadro de desenvolvimento da administração, porque nêle podia ver que administradores, estavam prontos para progredir e que dirigentes necessitavam de mais experiência ou treinamento para serem promovidos. 
Finalmente, os consultores pediram ao SR. $\cos \mathrm{T}_{\boldsymbol{A}}$ para completar o quadro de substituições, anotando, sob cada cargo administrativo, o nome do indivíduo que o assumiria, caso o tituar falecesse, adoecesse sèriamente ou inesperadamente abandonasse a companhia. JosÉ teve uma certa dificuldade com esta tarefa. A sua substituição não era difícil : êle havia planejado ceder seu lugar a FLÁvio em futuro não muito remoto. Se seu irmão paulo abandonasse a companhia repentinamente, êle poderia colocar seu filho JoÃo no lugar de PAULO.

No entanto, a escolha das demais substituições se tornou mais difícil, pois, entre outros problemas, não havia número suficiente de membros nas famílias cosTa e PEREIRA para preencher tôdas as tarefas importantes - particularmente em caso de expansão da emprêsa. Além disso, josé descobriu que não conhecia muito bem os elementos de níveis mais baixos de sua emprêsa. O elemento mais intimamente ligado aos empregados era seu assistente, SR. SCHMIDT. ADOLFO SCHMIDT, de 50 anos, que não é membro da família costa, trabalha na emprêsa quase desde seu início e conhece mais acêrca de suas operações do que qualquer outro, com exceção de José.

ScHMid tornar-se-ia, claramente, o melhor administrador de cúpula da emprêsa, mas o fato de não pertencer à família afastava-o da possibilidade de ser indicado para sucessor de JosÉ. Quando chegou a vez de indicar um substituto para SCHMIDT, JosÉ ficou completamente perdido. Não havia ninguém, dentro ou fora da família, que pudesse ocupar seu lugar.

Pela primeira vez, JosÉ verificou quão importante era SCHMIDT para a emprêsa. Foi, então, que decidiu começar imediatamente a treinar alguns de seus filhos e netos para substituí-lo. Apesar de schmidT gozar de boa saúde, não era aconselhável que a companhia dependesse tanto de um só indivíduo.

Outra coisa que o SR. costa aprendeu, ao fazer o quadro de substituições, foi que talvez pudesse dispensar NELSON, diretor de relações públicas, seu sobrinho. NELSON nunca havia dado atenção às suas responsabilidades na emprêsa e para 
ela entrara a pedido de sua mãe, irmã de JosÉ. Assim, José decidiu não fazer previsões para a substituição de NELSON, pois suas tarefas poderiam ser fàcilmente assumidas pelo departamento de scHMIDT ou pelo diretor comercial, se a emprêsa fôsse organizada de acôrdo com o organograma ideal (Quadro 2).

Finalmente, depois de muito pensar, o SR. cosTA completou o organograma de acôrdo com sua melhor possibilidade e mostrou-o aos consultores (Vide Quadro 4).

Tanto o SR. CosTA, como os consultores, compreenderam que havia um grande número de problemas a resolver antes de a "José Costa S/A" poder fazer planos de expansão em bases sólidas. Demasiado repousava nos ombros de schMIDT ou do próprio José costa. Se ambos tivessem que abandonar a firma, esta, indubitàvelmente, teria que cessar as atividades.

Poucas previsões haviam sido feitas para trazer jovens que não fôssem membros das famílias cosTa e PEREIRA para a companhia. Conseqüentemente, demasiado repousava nos ombros do único neto de costa, Flávio.

JosÉ costa verificou que necessitava começar a trazer mais gente de fora : ou faria isto, ou abandonaria os planos de expansão da emprêsa. Mas fracassar na expansão era correr o risco de, eventualmente, ser sobrepujado por outras emprêsas mais dinâmicas. JosÉ decidiu, então, que devia enfrentar o desafio do crescimento, mesmo que isso significasse entregar alguns dos postos de administração mais elevados a indivíduos que não pertencessem à família.

\section{Conclusões}

A história da "José Costa S/A", focalizada sôbre sua expansão e seus problemas de organização, serve bem para ilustrar de que forma o organograma pode auxiliar a emprêsa a planejar eficientemente sua expansão.

Quando se depara com as questões de como preparar uma organização para a expansão, como desenvolver a estrutura da organização e como preparar os administradores para di- 
rigir a emprêsa, o dirigente pode recorrer ao uso do organograma, pois êste, como instrumento ou técnica de organização, auxilia a emprêsa a planejar mudanças de indivíduos na administração, a treinar eventuais substitutos para os dirigentes da emprêsa e a fazer modificações na estrutura da organização .

Através da aplicação dos "princípios" ou "regras" de administração, poderá o administrador estabelecer a organização que seja mais apropriada, do ponto de vista da eficiência, ao tipo de emprêsa e ao pessoal de que dispõe. E o estabelecimento dessa organização tem, no organograma, meio útil e simples de ser verificado.

É, pois, o organograma arma administrativa que devem utilizar os administradores que desejam ver a expansão eficiente de suas emprêsas. 